\title{
Evaluation and statistical analysis of the modified QuEChERS method for the extraction of pinoxaden from environmental and agricultural samples
}

\author{
Mian Muhammad ${ }^{1 *}$ D, Muhammad Rasul Jan², Jasmin Shah², Behisht Ara², Sohail Akhtar ${ }^{3}$
} and Hafeez Ur Rahman ${ }^{1}$

\begin{abstract}
Background: Green chemistry focuses on an efficient extraction strategy for pesticides from agricultural and environmental samples. QuEChERS (quick, easy, cheap, effective, rugged, and safe) method is used primarily, in the extraction of pesticides from food matrices. Certain modifications in the approach lead to better sensitivity and efficient extraction. This paper describes an analytical approach for spectrophotometric determination of pinoxaden herbicide in different matrices based on a modified QuEChERS method.

Methods: The original QuEChERS method was modified using different buffering media and different cleanup sorbents. Efficacy of different dispersive SPE sorbents for the cleanup was compared. The optimized conditions were applied for investigation of percent recovery and residue analysis. The presence of the residue was confirmed by employing two reported HPLC methods under optimized conditions. Statistical analysis of the data was accomplished to investigate the distribution of the subject analyte in soil.

Results: The average percent recovery of pinoxaden was found to be in the range of $77 \pm 5 \%$ to $100 \pm 2 \%$ for soil, $84 \pm 2 \%$ to $98 \pm 2 \%$ for water samples, and $79 \pm 1 \%$ to $88 \pm 1 \%$ for wheat grains. Good linearity with $R^{2}=0.997$ was achieved in acetate buffer system. Limits of detection of pinoxaden in soil, water, and wheat grain samples were found to be $0.6 \mu \mathrm{g} / \mathrm{g}, 0.48 \mu \mathrm{g} / \mathrm{mL}$, and $0.31 \mu \mathrm{g} / \mathrm{g}$, respectively, while limits of quantification in the above matrices were found to be $1.83 \mu \mathrm{g} / \mathrm{g}, 1.46 \mu \mathrm{g} / \mathrm{mL}$, and $0.94 \mu \mathrm{g} / \mathrm{g}$ respectively. Statistical analysis of the data using a three-way ANOVA shows that the individual impacts of cardinal axis and time on distribution of pinoxaden (PXD) residue is statistically insignificant. However, the impact of depth on PXD residue was found to be highly significant as the $p$ value $<0.01$. The interaction of the sampling time and depth of soil was found to have highly significant effect on the PXD residue in soil sample.
\end{abstract}

Conclusions: The proposed method is a milestone in the extraction of pinoxaden, a relatively new pesticide, from agricultural and environmental samples in terms of simplicity, sensitivity, and reproducibility.

Keywords: QuEChERS, Cleanup, Pinoxaden, Pilot field, Three-way ANOVA

\footnotetext{
* Correspondence: mianchem@uom.edu.pk

${ }^{1}$ Department of Chemistry, University of Malakand, Khyber Pakhtunkhwa,

Pakistan

Full list of author information is available at the end of the article
} 


\section{Background}

Analysis of environmental as well as agricultural commodities for determination of pollutants especially, pesticides, is imperative for corrective and preventive planning concerning pollutants and human health. The steps commonly encountered in any analysis are sampling, sample preservation, sample preparation, and finally the chemical analysis. Sample preparation being the most important, challenging, labor-intensive, and time-consuming step involves homogenization, extraction, concentration, and cleanup (Anthemidis and Ioannou 2009; Liu et al. 2010).

While seeking for minimum solvent and reagent consumption and reduction of laboratory wastes, simplification and miniaturization of sample preparation procedures is the focus of green analytical chemistry (Miro et al. 2005; Anthemidis and Adam 2009).

Liquid-liquid extraction (LLE) is the most extensively used sample pre-treatment technique, for cleanup, enrichment, and signal enhancement (Anthemidis and Ioannou 2009). However, LLE is considered expensive, tedious, laborious, time consuming, environmentally unfriendly, and potentially disposed to sample contamination when ultratrace determinations are necessary and not applicable to hydrophilic compounds (Anthemidis and Miró 2009; Pena-Pereira et al. 2009; Zhang et al. 2009).

In conventional LLE, certain solvents, which are miscible with water in all proportion, cannot be used as extracting solvents. The adaptability of solvent extraction would be significantly improved if some way could be found to separate these solvents as organic phases from aqueous solutions (Anthemidis and Ioannou 2009).

Phase separation of some water-miscible organic solvents from the aqueous solution can be easily induced by addition of high concentration of a proper mixture of salts into aqueous sample solutions (Rustum 1989). Based on this hypothesis, salting-out assisted liquid-liquid extraction (SALLE) was introduced for sample treatment (Song et al. 2013). The salts help the polar analytes present in the aqueous phase to selectively move into the polar organic phase. In SALLE, water-miscible organic solvents are used as the extractants (Liu et al. 2010).

SALLE method was established as a sample preparation method based on a number of advantages such as simplicity, easy purification, and rapid partition equilibrium. For many separation processes, this method has been reported which include extraction of phthalate esters (Cai et al. 2007), removal and recovery of several metal chelates (Casas Ferreira et al. 2014; Matkovich and Christian 1974), determination of carbonyl compounds (Gupta et al. 2009), and determination of pharmaceutical compounds (Razmara et al. 2011).

QuEChERS (quick, easy, cheap, effective, rugged, and safe) extraction method, being a variant of the SALLE technique, adds an additional dispersive solid-phase extraction (dSPE) cleanup step after the partitioning of the organic phase and aqueous phase in the presence of salts. It is used primarily, in the extraction of pesticides from food matrices (Noche et al. 2011; García-Reyes et al. 2007; Hercegová et al. 2007; Gilbert-López et al. 2009; Wilkowska and Biziuk 2011; LeDoux 2011). In 2003, Anastassiades et al. (2003) introduced the QuEChERS method for determination of pesticide residues in vegetables and fruits. The procedure involves a single-phase extraction of the analyte with acetonitrile, following liquid-liquid partitioning, accomplished by the addition of anhydrous $\mathrm{MgSO}_{4}$ and $\mathrm{NaCl}$. Residual water is removed, and cleanup is performed simultaneously by using dSPE.

QuEChERS extraction method was originally developed for the multi-residue analysis of pesticides in produce (DeArmond et al. 2015). Nowadays, it is a sample preparation technique of choice for the analysis of a variety of chemicals in a variety of different samples. This method is employed for routine quantification of pesticides in products consumed by human (Albert et al. 2014, Rejczak and Tuzimski 2015).

Pinoxaden is a grass-specific herbicides used for the post emergence control of annual and perennial herbs in some cereal crops, i.e., wheat and barley. Though a large number of different methods have been described for the extraction of pesticides which are mainly chromatographic like HPLC (Huang et al. 2007; Lin et al. 2007), GC (Shah et al. 2010), and LC-MS (Díez et al. 2008), but no proper extraction strategy for pinoxaden (PXD) has so for been reported.

All of these methods require expensive instruments and sample cleanup procedure. To overcome the deficiency of traditional methods, QuEChERS procedure was developed to extract pesticides from fruits and vegetables. In the present research work, original QuEChERS extraction approach was modified for investigation of pinoxaden herbicides in different matrices such as water, grains, and agricultural soil samples. Different statistical methods of analysis were applied to investigate the spatio-cardinal distribution of PXD in soil in a pilot wheat field and to explore the individual and interactive impact of different parameters such as cardinal axis, sampling time after application, and depth of sampling site on PXD residue.

\section{Methods}

\section{Chemicals and reagents}

Sodium acetate (Uni-Chem/Avonchem, UK), trisodium citrate (Fisher Scientific, UK), disodium hydrogen citrate sesquihydrate, ethanol (purity $>99.9 \%$ ) and $\mathrm{NaCl}$ (Merck, Germany) were purchased through local vendors. Acetic acid, $\mathrm{NaOH}, \mathrm{MgSO}_{4} \cdot 7 \mathrm{H}_{2} \mathrm{O}$, methanol, and $\mathrm{MgSO}_{4}$-anhydrous were purchased from Sigma-Aldrich (Germany). 
Acetonitrile-HPLC grade (BioM Laboratories Cerritos, USA) and primary secondary amine (PSA) (Agilent Technologies, USA), pesticide standard (pinoxaden), Riedel de Haen, Dr. Ehrenstorfer, Promochem, Germany were purchased through local suppliers. Carbon black and sawdust were indigenously prepared. Real samples of soil, wheat grains, and water were collected from the pilot field situated in village Gumbat, Talsh, Dist. Dir (L) KP, Pakistan.

\section{Instruments, equipment, and software}

Centrifuge 5702 R (Eppendorf, AG 22331-Hamberg Germany) was used for centrifugation. UV-1800, UVspectrophotometer (Schimadzu Corporation, Japan) was used for measuring concentration versus signal response for optical analysis of the extracts. Automatic pipettes (1-10 $\mu \mathrm{L}, 200-1000 \mu \mathrm{L}$, and 1-10 mL) and disposable 50-mL centrifuge tubes with screw caps (e.g., $114 \times$ $28 \mathrm{~mm}$, PP, Sarstedt, article-no. 62.548.004) were employed during reagents transfer and centrifugation. SPSS V-20 was used for statistical analysis.

\section{Extraction procedures and measurements}

Original unbuffered QuEChERS extraction procedure was followed after optimization of the optical properties of the pesticides' standards. The original unbuffered
QuEChERS extraction method was modified using citrate and acetate buffer system, and efficiency of each was validated by applying relative statistics. Similarly, efficacy of various solid phases such as PSA, carbon black, and indigenously prepared sawdust was investigated for the cleanup step. All the reagent concentrations in terms of the mass of salts were optimized, and optimum conditions were applied for real sample analysis. A schematic representation of the method is shown in Fig. 1.

For application of the method to environmental samples like soil, wheat grains, and water, $10 \mathrm{~g}$ or $10 \mathrm{~mL}$ of the sample was transferred into a $50-\mathrm{mL}$ polypropylene centrifuge tube. $4.0 \mathrm{~mL}$ of ultrapure water was added and mixed manually, for $1 \mathrm{~min}$. Subsequently, $20 \mathrm{~mL}$ of $\mathrm{MeCN}$ (1\% HOAc) were added, the mixture was shaken vigorously for $2 \mathrm{~min} .6 .0 \mathrm{~g}$ of $\mathrm{MgSO}_{4}$ and $1.8 \mathrm{~g}$ of $\mathrm{NaOAc} \cdot 3 \mathrm{H}_{2} \mathrm{O}$ or a mixture of trisodium citrate and disodium hydrogen citrate sesquihydrate were added depending upon the buffer desired, shaken as quick as possible to prevent formation of $\mathrm{MgSO}_{4}$ conglomerates and centrifuged for $5 \mathrm{~min}$ at $4000 \mathrm{rpm}$. A cleanup step was carried out on a $15-\mathrm{mL}$ aliquot. The aliquot was shaken with optimized mass of different sorbents such as PSA, carbon black, and sawdust in batch cleaning and centrifuged for optimized time of $2 \mathrm{~min}$ at $4000 \mathrm{rpm}$. The supernatants were transferred into vials, added

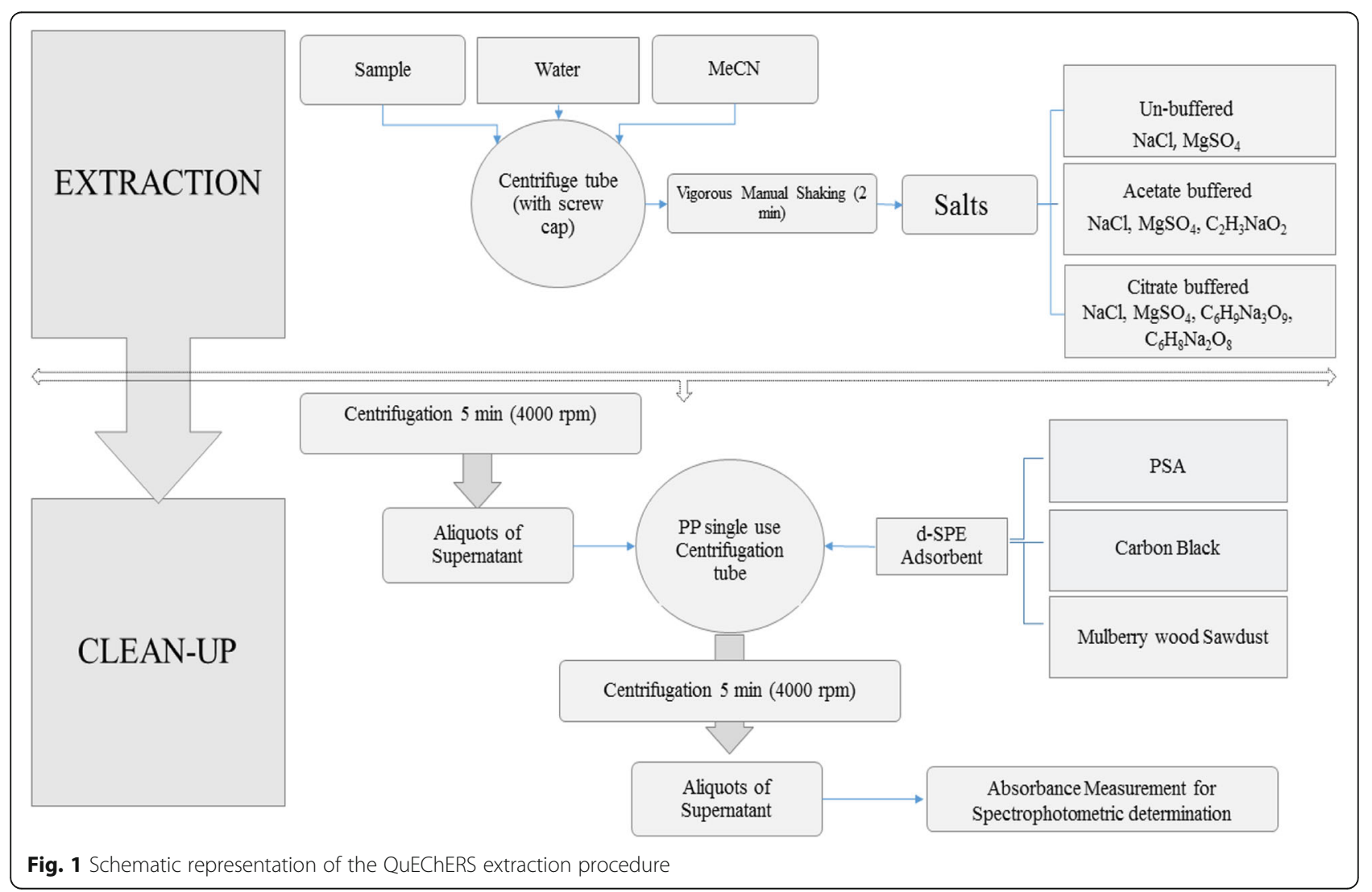


$5.0 \mathrm{~mL}$ of methanol and analyzed through UV-1800, UV/VIS spectrophotometer by measuring the absorbance at $260 \mathrm{~nm}$. A schematic representation of the method is shown in Fig. 1.

\section{Optimization of QuEChERS extraction conditions}

In order to achieve the best possible extraction results, a number of parameters that influence the extraction efficiency were investigated and the optimal conditions were employed in the subsequent analyses. The important parameters being optimized include mass of the salts $\left(\mathrm{NaCl}\right.$ and $\left.\mathrm{MgSO}_{4}\right)$ in original QuEChERS extraction, mass of sodium acetate in acetate buffered extraction, and mass of disodium hydrogen citrate sesquihydrate and trisodium citrate in citrate buffered extraction.

The efficiency of a variety of sorbents for dispersiveSPE cleanup was investigated by examining the recovery of the analyte using different sorbents such as PSA, carbon black, and indigenously prepared sawdust.

\section{Sampling}

A $100 \times 100$-m field of wheat crop was selected in village Gumbat, Talash, Dist. Dir (L), as pilot field. The formulation of the subject pesticides (Axial; EC 9.8\% w/w) was sprayed, following proper procedures and precautions. The soil, water, and wheat samples were collected from surface and form a pre-defined depth of 6 and 12 in. following a pre-defined sampling plan. The samples were preserved in plastic bottles at $4{ }^{\circ} \mathrm{C}$ in a refrigerator and were analyzed within $48 \mathrm{~h}$ after sampling. For the method optimization, the samples were collected from the same area but from the field where the target pesticides had not been sprayed.

\section{Recovery studies}

Soil, water, and wheat grain samples, collected from the nearby places of the pilot field, were carried and subjected to the optimized acetate buffered QuEChERS procedure in order to confirm the presence or absence of PXD. After the endorsement of absence of PXD, the samples were employed for the fortification experiments. Mixtures were spiked in triplicate in the range of LOQ and 10 LOQs. The spiked samples were left for $2 \mathrm{~h}$ for equilibration of the pesticide with the samples. The optimized acetate buffered QuEChERS extraction procedure was then followed for extraction.

\section{Residue analysis}

The collected and preserved samples of soil, wheat grains, and water were subjected to residue analysis. The soil samples were crushed with the help of mortar and pistil to achieve homogeneity. The test sample was enough homogeneous that sub-sampling variability was acceptable. In case of soil samples, a homogenized $5.0-\mathrm{g}$ test sample of the comminuted homogenous sample was taken in each of a series of $50-\mathrm{mL}$ centrifuge tubes. Water was added leading to a total water content in the tube of approximately 10 g. $7.5 \mathrm{~mL}$ of $1 \%$ acetic acid solution in acetonitrile was added to each tube. Each tube was closed and shaken vigorously for $1 \mathrm{~min}$ followed by the addition of buffering salts $\left(2.0 \mathrm{~g} \mathrm{MgSO}_{4}\right.$ and $1.5 \mathrm{~g}$ $\mathrm{CH}_{3} \mathrm{CHOONa}$ ) and shaken vigorously for $1 \mathrm{~min}$. The mixture in each case was centrifuged for $2 \mathrm{~min}$ at $4000 \mathrm{rpm}$. The supernatant was taken and transferred to dispersive SPE centrifuge tube containing $\mathrm{MgSO}_{4}$ (150 mg) and sorbent PSA (50 mg) for each milliliter of extract, vigorously shaken and centrifuged. Each aliquot was transferred to a quartz cuvette, and the absorbance was measured against matrix matched blank at $260 \mathrm{~nm}$ using UV-VIS spectrophotometer. Concentration in each case was calculated, and the data was subjected to statistical analysis. The wheat grain samples and the preserved water samples were analyzed following the same procedures as discussed above.

\section{Statistical analysis}

In order to convert the figures into facts, the data obtained as a result of analysis was subjected to statistical treatment. Standard deviation (SD), relative standard deviation (RSD), limit of detection (LOD), limit of quantification (LOQ), and correlation coefficient of the method were calculated. A three-way ANOVA (general linear model) was employed to investigate the significance of different factors and their interactive influence on the PXD residue in soil. These factors include cardinal axis, time of sampling after application, and depth of the sampling site. One-way analysis of variance was used to find out the impact of cardinal axis on residue of PXD in wheat grains.

\section{Results and discussion \\ Optimization of experimental conditions}

The original QuEChERS method was modified to accommodate the instrumentation, samples, and operations available at the Department of Chemistry, University of Malakand.

This study is focused on the investigation of the efficacy of QuEChERS extraction methods for PXD from environmental samples of soil, wheat grains, and water. QuEChERS extraction involves two main steps: the extraction and cleanup. The effects of a variety of physical and chemical parameters on the extraction as well as cleanup steps were investigated. The effect of mass of buffering and dehydrating salts and nature of buffer on the extraction was studied. The comparative study of the unbuffered and buffered QuEChERS extraction strategies was explored. The influence of nature of sorbent on the cleanup step was also investigated. The extraction 
Table 1 Effect of mass of different reagent on various QuEChERS methods

\begin{tabular}{llccc}
\hline No. & Reagent & $\begin{array}{c}\text { Mass range } \\
\text { used }(\mathrm{g})\end{array}$ & $\begin{array}{c}\text { Optimum } \\
\text { mass }(\mathrm{g})\end{array}$ & Remarks \\
\hline 1. & Magnesium sulfate $\left(\mathrm{MgSO}_{4}\right)$ & $1.0-8.0$ & 2.0 & $\mathrm{a}$ \\
2. & Sodium chloride $(\mathrm{NaCl})$ & $0.5-4.0$ & 2.0 & \\
3. Sodium acetate $\left(\mathrm{CH}_{3} \mathrm{COONa}\right)$ & $0.5-6.0$ & 5.0 & $\mathrm{~b}$ \\
4. & $\begin{array}{l}\text { Trisodiumcitrate dihydrate } \\
\text { HOC }(\mathrm{COONa})\left(\mathrm{CH}_{2} \mathrm{COONa}\right)_{2} \cdot 2 \mathrm{H}_{2} \mathrm{O}\end{array}$ & $0.25-2.0$ & 1.5 & \\
5. & & & \\
& $\begin{array}{l}\text { Disodiumhydrogencitrate } \\
\text { sesquihydrate }\end{array}$ & $0.25-2.0$ & 0.5 & \\
$\left(\mathrm{Na}_{2} \mathrm{HC}_{6} \mathrm{H}_{5} \mathrm{O}_{7}\left(\mathrm{H}_{2} \mathrm{O}\right)_{1.5}\right)$ & & & \\
\hline
\end{tabular}

${ }^{a}$ Minimum miscibility and maximum phase separation at optimum concentration of ions of the respective salt lead to maximum recovery. Beyond the optimum the ions saturated system causes the analyte to be water soluble leading to a decrease in the recovery

${ }^{b}$ Maximum buffering action at optimum mass where the PXD molecules are preserved against degradation results in optimum recovery

efficiency in terms of percent recovery from various samples was investigated. Residue analyses of PXD herbicide in soil, wheat grains, and water samples were also accomplished. The data obtained was subjected to statistical analysis for obtaining fruitful conclusions about the individual and interactive impact of a number of parameters on PXD residue and also about the cardinal and spatio-temporal distribution of the subject herbicide in soil and wheat grains.

Effect of mass of reagents on QuEChERS extraction of PXD In order to obtain best possible results and maximum possible recoveries, the effect of mass of different reagents on various QuEChERS methods was investigated. The effect of mass of $\mathrm{MgSO}_{4}$ and $\mathrm{NaCl}$ for the extraction of PXD was investigated using unbuffered version of QuEChERS approach. The effect of the mass of sodium acetate on the extraction of PXD was studied using acetate buffered version while that of the mass of trisodiumcitrate dihydrate and disodiumhydrogencitrate sesquihydrate in case of citrate buffered of QuEChERS approach was investigated. The samples were spiked with different volume of PXD $(100 \mu \mathrm{g} / \mathrm{mL})$ till the final concentration become $1.0 \mu \mathrm{g} / \mathrm{mL}$. The absorbance of the clean aliquots was measured against the method blank. The results are given in Table 1.

\section{Comparison of the extraction strategies}

In order to compare the results of the three extraction strategies, all were applied for extraction of PXD from spiked samples of soil, wheat, and water with spiking level of $1.0 \mu \mathrm{g} / \mathrm{g}$ or $1.0 \mu \mathrm{g} / \mathrm{mL}$ as the case may be. All the procedures were carried out in triplicates. The acetate buffered method was found to show better recoveries. The results are given in Table 2 . The $\mathrm{pH}$ of the final extract is a decisive parameter that influences the performance of the extraction procedure. Compared to the acetate buffered extract having a nominal $\mathrm{pH} 4.8$, the citrate buffered extract has an average $\mathrm{pH}$ near 6. Pinoxaden is a base-sensitive pesticide and is more stable to degradation/ionization at lower $\mathrm{pH}$. Due to this very reason, the recovery in case of acetate buffered procedure is higher than the unbuffered as well as the citrate buffered procedures (Lehotay et al. 2010).

\section{Effect of cleanup sorbents on QuEChERS extraction of PXD}

The cleaning up is a key step in the whole QuEChERS method. For cleaning up, a number of different sorbents were used and a comparative study of carbon black, primary-secondary amine (PSA), and indigenous sawdust as cleanup sorbents for soil, wheat grains, and water samples was done. The results are shown in Fig. 2. The figure shows that the efficiency of indigenously prepared sawdust as cleanup sorbent is comparable to the very expensive sorbents, i.e., carbon black and PSA, and shows good recoveries of PXD from the target samples. The findings open a door for the use of indigenous sawdust as d-SPE sorbent in commercial QuEChERS extraction kits.

\section{Study of soil texture}

The interaction of soil with the target pesticides has an important role in its dissipation and leaching down

Table 2 Comparison of the buffered and unbuffered extraction strategies

\begin{tabular}{|c|c|c|c|c|c|c|c|}
\hline \multirow[t]{2}{*}{ Sample } & \multirow{2}{*}{$\begin{array}{c}\text { Spiking level } \\
(\mu \mathrm{g} / \mathrm{g}, \mu \mathrm{g} / \mathrm{mL})\end{array}$} & \multicolumn{3}{|c|}{$\mu \mathrm{g}$ found } & \multicolumn{3}{|c|}{ Average $\%$ recovery $\pm S D$} \\
\hline & & Unbuffered & Acetate buffered & Citrate buffered & Unbuffered & Acetate buffered & Citrate buffered \\
\hline \multirow[t]{3}{*}{ Soil } & 1.0 & 0.79 & 1.08 & 0.92 & $84 \pm 5$ & $102 \pm 5$ & $93 \pm 3$ \\
\hline & 1.0 & 0.84 & 0.98 & 0.91 & & & \\
\hline & 1.0 & 0.89 & 1.01 & 0.97 & & & \\
\hline \multirow[t]{3}{*}{ Wheat grains } & 1.0 & 0.93 & 1.11 & 0.89 & $93 \pm 4$ & $102 \pm 8$ & $93 \pm 5$ \\
\hline & 1.0 & 0.88 & 0.94 & 0.91 & & & \\
\hline & 1.0 & 0.97 & 1.02 & 0.98 & & & \\
\hline \multirow[t]{3}{*}{ Water } & 1.0 & 0.76 & 1.01 & 0.95 & $83 \pm 10$ & $99 \pm 2$ & $94 \pm 6$ \\
\hline & 1.0 & 0.79 & 0.98 & 0.99 & & & \\
\hline & 1.0 & 0.94 & 0.97 & 0.87 & & & \\
\hline
\end{tabular}




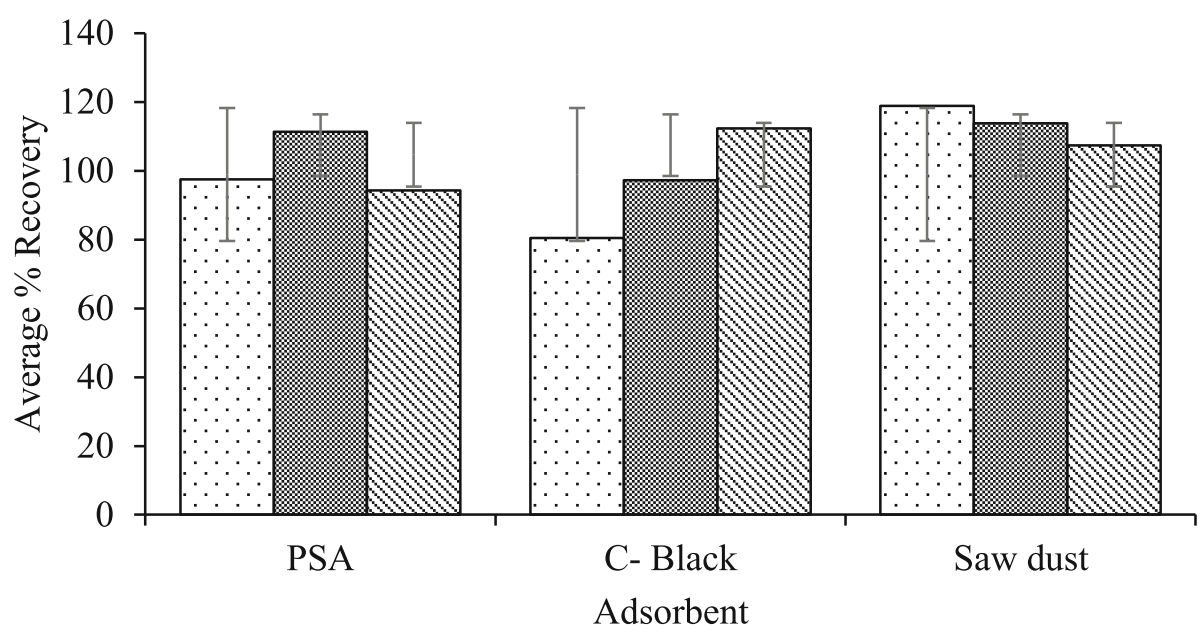

$\square$ Soil $⿴$ Wheat Grains $⿴ 囗$ Water

Fig. 2 Comparison of the cleanup sorbents used in modified QuEChERS approach for extraction of PXD: spiking level $0.5 \mu \mathrm{g} / \mathrm{g}$. Error bars signify standard error $(n=3)$

through the soil matrix. The soil texture was characterized and the results are given in Table 3 . The soil samples collected from the surface, at a depth of $6 \mathrm{in}$. and that at $12 \mathrm{in}$., were found to contain $5-10 \%$ clay, $45.7-$ $58 \%$ silt, and $35-43.6 \%$ sand. Mostly, the soil of the pilot field is sandy loam or loamy and allows the pesticide to percolate easily into the soil.

\section{Recovery studies}

For recovery studies of PXD from soil, water and wheat grain samples, the unsprayed samples of target area were spiked with the PXD and percent recovery of the analyte investigated. The results are shown in Table 4. The percent recovery of PXD was found in the range of $77 \pm 5 \%$ to $100 \pm 2 \%$ for soil, $84 \pm 2$ to $98 \pm 2 \%$ for water samples, and $78 \pm 1 \%$ to $88 \pm 2 \%$ for wheat grains.

\section{Residue analysis}

Real sample of soil collected from pilot field was analyzed for PXD employing the acetate buffered extraction. Residues of PXD were detected in all the samples in the concentration range of $1.2-9.12 \mu \mathrm{g} / \mathrm{g}$.

Magnitude of PXD residues varied greatly among the study areas. Maximum residue of PXD was found in the samples collected from north and west sampling spots of the field. This can be simply attributed to the fact that the pilot field is steep from east and south downwards to north and west. Similarly, the spatio-temporal distribution study of PXD in soil samples shows that residue is higher in the surface samples collected after $6 \mathrm{~h}$, while as the time for sample collection after the application (spray) increases the concentration of the analyte decreases. This fact can be explained on the basis of the assumption that with the passage of time, the herbicide leaches into the ground and the surface samples have lower concentration of PXD. Similarly, with the passage of time, the concentration of PXD increases in the samples collected from deeper regions of the soil. It is because the penetration of the sample molecules is a slow process, and they find sufficient time to leach deep into the ground to a depth of $12 \mathrm{in}$.

The wheat grain samples were analyzed following the same procedures as discussed previously. Wheat grain samples have PXD residues in the range of 1.58$4.51 \mathrm{\mu g} / \mathrm{g}$, and the cardinal distribution shows that the wheat samples collected from western spots of the pilot field have high concentration of PXD.

The preserved water samples were analyzed for PXD residues following the same procedures where applicable and mentioned in experimental section. Water samples have PXD residues in the range of $2.62-4.03 \mu \mathrm{g} / \mathrm{mL}$.

Table 3 Texture analysis of soil samples

\begin{tabular}{|c|c|c|c|c|c|c|c|c|}
\hline No. & Sample code & First reading (silt + clay) & Clay (\%) & Silt (\%) & Sand (\%) & Second reading (clay) & Type found & Weight (g) \\
\hline 1. & PXD Surface & $\begin{array}{c}\text { Hyd }=27 \\
\text { Temp }=23.5^{\circ} \mathrm{C}\end{array}$ & 8.4 & 47.7 & 43.9 & $\begin{aligned} \text { Hyd } & =27 \\
\text { Temp } & =24^{\circ} \mathrm{C}\end{aligned}$ & Sandy loam & 50 \\
\hline 2. & PXD 6 in. & $\begin{array}{c}\text { Hyd }=26 \\
\text { Temp }=23.5^{\circ} \mathrm{C}\end{array}$ & 5 & 58 & 37 & $\begin{array}{c}\text { Hyd }=3 \\
\text { Temp }=23.5^{\circ} \mathrm{C}\end{array}$ & Silt loam & 43 \\
\hline 3. & PXD 12 in. & $\begin{array}{c}\text { Hyd }=27 \\
\text { Temp }=23.5^{\circ} \mathrm{C}\end{array}$ & 10.4 & 45.7 & 43.9 & $\begin{array}{c}\mathrm{Hyd}=4 \\
\text { Temp }=24^{\circ} \mathrm{C}\end{array}$ & Sandy loam or loam & 50 \\
\hline
\end{tabular}


Table 4 Percent recovery of PXD extracted with the modified QuEChERS method

\begin{tabular}{|c|c|c|c|c|c|c|}
\hline \multirow[t]{2}{*}{ Sample } & \multirow{2}{*}{$\begin{array}{l}\text { Spiking level } /(\mu \mathrm{g} / \mathrm{g}) \\
\text { or }(\mu \mathrm{g} / \mathrm{mL})\end{array}$} & \multicolumn{3}{|c|}{ Recovery (\%) } & \multirow{2}{*}{$\begin{array}{l}\text { Average } \\
\text { recovery (\%) }\end{array}$} & \multirow{2}{*}{$\begin{array}{r}\text { RSD } \\
(\%)\end{array}$} \\
\hline & & 1 & 2 & 3 & & \\
\hline \multirow[t]{3}{*}{ Soil } & 1.0 & 73.0 & 76.0 & 82.0 & 77.0 & 4.6 \\
\hline & 5.0 & 92.6 & 97.4 & 93.5 & 94.5 & 10.6 \\
\hline & 10.0 & 100.3 & 99.3 & 99.8 & 99.8 & 1.9 \\
\hline \multirow[t]{3}{*}{ Water } & 1.0 & 83.0 & 86.0 & 82.0 & 83.6 & 2.1 \\
\hline & 5.0 & 82.6 & 87.4 & 88.5 & 86.2 & 3.1 \\
\hline & 10.0 & 97.3 & 96.4 & 99.8 & 97.8 & 1.8 \\
\hline \multirow{3}{*}{$\begin{array}{l}\text { Wheat } \\
\text { grains }\end{array}$} & 3.0 & 79.0 & 81.5 & 82.7 & 81.1 & 1.9 \\
\hline & 15.0 & 77.6 & 79.4 & 78.2 & 78.4 & 0.91 \\
\hline & 30.0 & 87.2 & 86.4 & 89.3 & 87.6 & 1.5 \\
\hline
\end{tabular}

Confirmation of the presence of PXD residue in soil and wheat grains using HPLC analysis

Identification of the components of the natural samples by UV/VIS spectrophotometery alone is decisively not sufficient. Therefore, it is necessary to confirm their presence in the samples using a sophisticated instrumental technique. In order to confirm the presence of PXD in the subject samples, the optimized experimental conditions of two reported HPLC methods (Siebers et al. 2014; Shehzad and Shah 2013) were employed. The optimized conditions of the two methods are given in Table 5 .

Composite samples were prepared from gross samples collected at different depths from each cardinal axis. The representative samples (5.0 g each) were extracted using the acetate buffered extraction under the optimized conditions and were analyzed using HPLC system of the reported methods. The average residues found in the subject samples are given in Table 6. The results confirm the validity of the proposed method for extraction of PXD from soil and wheat grain samples.

\section{Statistical analysis of the effect of different parameters on the PXD residue in soil}

To find out the individual and interactive significance of different factors on the PXD residue in soil, a three-way ANOVA (general linear model) was employed. The results given in Table 7 and shown in Fig. 3 indicate that the individual impacts of cardinal axis and time were found statistically insignificant. However, the impact of
Table 6 Residue of PXD found in real samples of soil and wheat grains

\begin{tabular}{lllll}
\hline Sample & $\begin{array}{l}\text { Cardinal } \\
\text { axis }\end{array}$ & \multicolumn{3}{l}{ Average residue found $(\mu \mathrm{g})( \pm \mathrm{RSD})$} \\
\cline { 3 - 5 } & North & $3.7(0.4)$ & $3.3(0.6)$ & $3.4(1.0)$ \\
\hline Soil & South & $2.9(0.3)$ & $2.9(0.7)$ & $2.8(0.7)$ \\
& East & $2.7(0.2)$ & $2.8(0.2)$ & $2.5(0.9)$ \\
& West & $3.9(0.2)$ & $3.6(0.5)$ & $3.2(0.4)$ \\
\multirow{4}{*}{ Wheat grains } & North & $2.8(0.5)$ & $2.3(0.2)$ & $2.6(0.4)$ \\
& South & $2.4(0.7)$ & $1.3(0.4)$ & $2.0(0.6)$ \\
& East & $1.5(0.6)$ & $1.4(0.2)$ & $1.6(0.3)$ \\
& West & $4.9(0.6)$ & $4.5(0.8)$ & $4.5(0.7)$ \\
\hline
\end{tabular}

depth on PXD residue was found highly significant as the $p$ value $<0.01$ and this is an ideal situation predicted by the model. The analysis (Table 7 ) also predict that there is no significant effect of the interaction of cardinal axis (F1) and sampling time (F2) on the residue level of PXD. The same is the situation in case of the combined effect of cardinal axis (F1) and the depth of soil (F3). On the other hand, the interaction of the sampling time (F2) and depth of soil (F3) was found to have highly significant effect on the PXD residue in soil samples as depicted by the $p$ value $<0.01$.

To check the accuracy of the model, the coefficient of determination $\left(R^{2}\right)$ which shows the explanatory power of the model was also calculated. Its value $(0.889)$ means that the model applied is good fit for the explanation of the impact of various factors on PXD residue in soil samples.

One-way analysis of variance was used to find out the impact of cardinal axis on residue of PXD in wheat grains. The cardinal axis factor was found insignificant as the $p$ value is greater than 0.05 as shown in Table 8 .

\section{Investigation of the matrix effect}

Soil and wheat grains are very complex matrices, and their extraction by aqueous organic solvent mixtures often leads to the presence of coextracted matrix components in the final extract to be analyzed. The extent of matrix effects in PXD residue analysis of soil, water, and wheat grain samples prepared by the QuEChERS sample preparation method was investigated. To demonstrate matrix effect (ME) (\%), calibration curves (final concentration range 1,

Table 5 Experimental conditions for HPLC analysis of PXD in soil and wheat grain samples

\begin{tabular}{lccccc}
\hline Experimental conditions & & & & \\
\hline Method & Solvent & $\begin{array}{c}\text { Injection volume } \\
(\mu \mathrm{L})\end{array}$ & Mobile phase & $\begin{array}{c}\text { Flowrate } \\
(\mathrm{mL} / \mathrm{min})\end{array}$ & $\begin{array}{c}\text { Wavelength } \\
(\mathrm{nm})\end{array}$ \\
$\begin{array}{l}\text { Method 1 } \\
\text { Siebers et al. 2014 }\end{array}$ & $\mathrm{CH}_{3} \mathrm{CN}$ & 10 & $\mathrm{CH}_{3} \mathrm{CN} / 0.1 \% \mathrm{H}_{3} \mathrm{PO}_{4} 50+50$ & 3.0 & 260 \\
$\begin{array}{l}\text { Method 2 } \\
\text { Shehzad and Shah 2013 }\end{array}$ & $\mathrm{CH}_{3} \mathrm{CN}$ & 20 & $\mathrm{CH}_{3} \mathrm{CN} / \mathrm{CH}_{3} \mathrm{OH} 50+50$ & 5.0 & 260 \\
\hline
\end{tabular}


Table 7 Three-way analysis of variance to test the between-subjects effects on PXD residue in soil

\begin{tabular}{lcccccc}
\hline Source & DF & Seq SS & Adj SS & Adj MS & $F$ & $P$ value \\
\hline Cardinal axis (F1) & 4 & 10.556 & 10.556 & 2.6389 & 2.168 & 0.103307 \\
Time (F2) & 3 & 7.908 & 7.908 & 2.6361 & 2.165 & 0.118356 \\
Depth (F3) & 2 & 62.133 & 62.133 & 31.066 & 25.523 & 0.000001 \\
F1 $\times$ F2 & 12 & 25.579 & 25.579 & 2.1316 & 1.751 & 0.117300 \\
F1 $\times$ F3 & 8 & 12.354 & 12.354 & 1.5442 & 1.269 & 0.305079 \\
F2 $\times$ F3 & 6 & 115.171 & 115.17 & 19.195 & 15.770 & 0.000000 \\
Error & 24 & 29.213 & 29.213 & 1.2172 & & \\
Total & 59 & 262.913 & & & & \\
\hline R & & & & & &
\end{tabular}

$R^{2}=0.889$ (adjusted $R^{2}=0.727$ )

5 , and $10 \mu \mathrm{g} / \mathrm{g}$ or $\mu \mathrm{g} / \mathrm{mL}$ as the case may be) for standards in solvent were plotted versus calibration curves for matrix-matched standards. The matrix effect for different samples was calculated using expression (1). The data slope in matrix versus slope in standard solvent demonstrates the extent of the matrix effect.

$$
\operatorname{ME}(\%)=\left(S_{\mathrm{m}} / S_{\mathrm{s}} \times 100\right)-100
$$

where $S_{\mathrm{m}}$ is the slope in matrix and $S_{\mathrm{s}}$ is the slope in solvent. $0 \%$ ME means no matrix effect, 20 to $-20 \% \mathrm{ME}$ means mild matrix effect, from 20 to 50 or $(-20)$ to $(-50) \%$ means medium matrix effect, and above this means strong matrix effect. The \% ME for all the three matrices (soil, wheat grains, and water) as given in Table 9 were found to be from -5 to 8 means no or very little matrix effect. Here, the negative values indicate suppression of the signal due to matrix and the positive values are a sign of matrix enhancement.

\section{Investigation of validity of the method}

A set of performance characteristics that were in compliance with the recommendations and guide lines defined by the Commission Decision 2002/657/EC and Regulation EC/401/2006 were evaluated. Validation parameters assessed were linearity, accuracy (recovery), sensitivity (limit of detection and limit of quantification), repeatability (intraday precision; $\mathrm{RSD}_{\mathrm{r}}$ ), reproducibility (inter-day precision; $\mathrm{RSD}_{\mathrm{R}}$ ), and specificity.

In all matrices (soil, wheat grains, and water), linearity was assessed using matrix-matched calibration (MMC) curves, by spiking blank samples with different volume of PXD solution $(100 \mu \mathrm{g} / \mathrm{mL})$ to have a final concentration in the range $0.5-10 \mu \mathrm{g} / \mathrm{mL}$ or $\mu \mathrm{g} / \mathrm{g}$ as the case may be and extracted using the acetate buffered version of QuEChERS approach in optimized conditions of reagents concentration. The absorbance $(y)$ versus the concentration of analytes $(x)$ plots was linear in all the three matrices (soil, wheat grains, and water) over the tested concentration
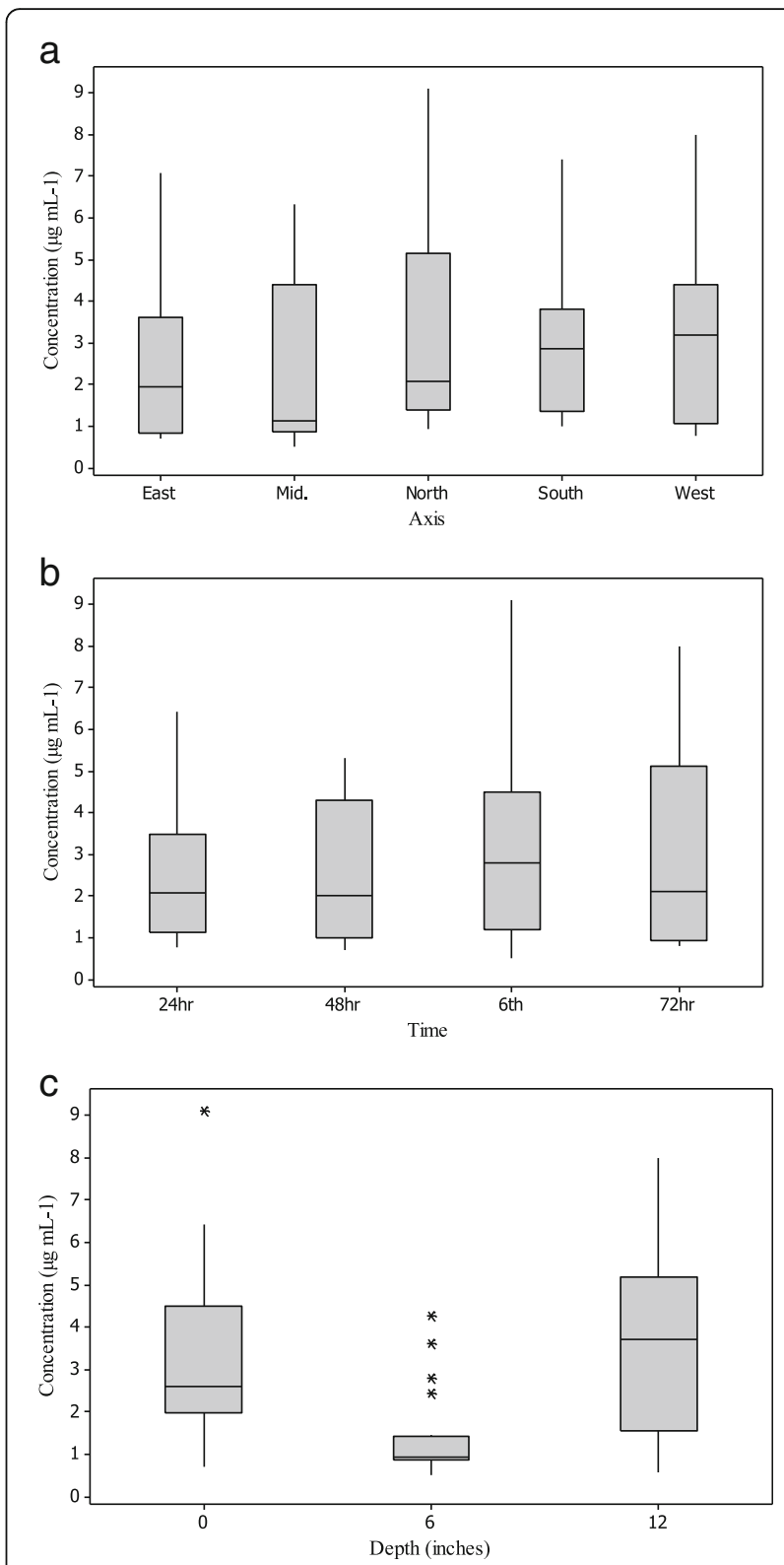

Fig. 3 Box-and-whisker plot of concentration versus a cardinal axis, b sampling time after application, and $\mathbf{c}$ depth of the sampled soil

range of $0.5-10 \mu \mathrm{g} / \mathrm{mL}$ or $\mu \mathrm{g} / \mathrm{g}$ as the case may be with coefficients of determination $\left(R^{2}=0.997\right)$.

The accuracy of the method was assessed in terms of recovery. According to IUPAC, the apparent recovery is the ratio of the predicted value obtained from the

Table 8 One-way analysis of variance of the impact of cardinal axis on PXD residue in wheat grains

\begin{tabular}{llllll}
\hline Source of variation & SS & DF & MS & $F$ & $P$ value \\
\hline Between groups & 16.731 & 4 & 4.183 & 0.821 & 0.541 \\
Within groups & 50.950 & 10 & 5.095 & & \\
Total & 67.681 & 14 & & & \\
\hline
\end{tabular}


Table 9 Investigation of Validity of the Method

\begin{tabular}{|c|c|c|c|c|c|c|c|c|}
\hline \multirow[t]{2}{*}{ Sample } & \multirow{2}{*}{$\begin{array}{l}\% \\
\mathrm{ME}\end{array}$} & \multirow{2}{*}{$\begin{array}{l}\text { Linearity } \\
R^{2}\end{array}$} & \multirow[t]{2}{*}{ Liner equation } & \multirow{2}{*}{$\begin{array}{c}\text { Accuracy } \\
\% \text { Recovery } \pm \text { SD }\end{array}$} & \multicolumn{2}{|c|}{ Precision } & \multicolumn{2}{|c|}{ Sensitivity $(\mu \mathrm{g} / \mathrm{mL}$ or $\mu \mathrm{g} / \mathrm{g})$} \\
\hline & & & & & $\% \mathrm{RSD}_{\mathrm{r}}$ & $\% \mathrm{RSD}_{\mathrm{R}}$ & LODs & LOQs \\
\hline Soil & 8 & 0.997 & $y=0.0590 x+0.0703$ & $93 \pm 1$ & 16.09 & 16.89 & 0.60 & 1.83 \\
\hline Water & 1 & 0.997 & $y=0.0553 x+0.0628$ & $96 \pm 2$ & 17.84 & 18.12 & 0.48 & 1.46 \\
\hline Wheat grains & -5 & 0.979 & $y=0.0519 x+0.0687$ & $79 \pm 1$ & 10.47 & 10.39 & 0.31 & 0.94 \\
\hline
\end{tabular}

matrix-matched calibration (MMC) curves divided by the actual/theoretical value. The recovery studies were performed at three spiked levels with six replicates at optimized condition. Recoveries of the PXD from matrices like soil, wheat grains, and water are given in Table 4 . The results showed that the mean recovery of PXD was between 79 and $96 \%$.

Precision of the method was assessed by repeatability and reproducibility experiments. Repeatability (intraday precision; $\mathrm{RSD}_{\mathrm{r}}$ ) of the method was evaluated by spiking the samples of soil, wheat grains, and water in four different concentration levels $(n=6)$ and analyzing on same day and same instrument, UV spectrophotometer (Table 9).

Reproducibility (inter-day precision; $\mathrm{RSD}_{\mathrm{R}}$ ) of the method was determined by repeating these experiments consecutively for three different days for all matrices (Table 9). This accuracy (recovery 79-96\%) and precision (\% RSD $\leq 20 \%$ ) was in accordance with method performance acceptability criteria. Sensitivity of the method was evaluated by limits of detection (LODs) and limits of quantification (LOQs). LOD refers to least detectable amount, and LOQs was defined as the minimum fortified level of recovery study.

The LODs and LOQs were obtained using the following expressions 2 and 3.

$$
\begin{aligned}
& \text { LOQs }=3.3 \sigma / s \\
& \text { LOQs }=10 \sigma / s
\end{aligned}
$$

where $\sigma$ is the standard deviation of the curve and $s$ is the slope of the curve.

The specificity of the method was evaluated by analyzing the blank samples and spiked soil, wheat grains, and water samples with PXD in the concentration range of $0.5-10 \mu \mathrm{g} / \mathrm{g}$ or $\mu \mathrm{g} / \mathrm{mL}$ as the case may be and extracted using the acetate buffered version of QuEChERS approach and matrix interferences were checked.

\section{Conclusions}

A simplified quick, easy, cheap, effective, rugged, and safe (QuEChERS) approach coupled with spectrophotometric detection was used for extraction of PXD herbicides from agricultural samples. Based on the original QuEChERS method, some parameters were modified according to the nature of matrices of soil, wheat grains, and water samples. Quantification of these herbicides in the target samples collected from a pilot field in Dist. Dir was performed with percent recovery in the range of 77-99.8\%. The method shows better accuracy and precision and was validated through a variety of statistical parameters. The method shows minimal \% matrix effect and can be applied to different related matrices. The approach was successfully applied for PXD residue determination, and the data obtained was subjected to rigorous statistical evaluation in order to investigate the significance of individual and interactive impact of different parameters on the PXD residue in soil, water, and wheat grain samples. The proposed method is a milestone in the extraction of pinoxaden, a relatively new pesticide, from agricultural and environmental samples in terms of simplicity, sensitivity, cost effectiveness, and reproducibility. The better recoveries with indigenous sawdust as d-SPE sorbent also suggest the use of this sorbent in commercially available kits for QuEChERS extraction.

\section{Abbreviations}

ANOVA: Analysis of variance; KP: Khyber Pakhtunkhwa; LLE: Liquid-liquid extraction; LOD: Limit of detection; LOQ: Limit of quantification; ME: Matrix effect; PSA: Primary secondary amine; PXD: Pinoxaden; QuEChERS: Quick, easy, cheap, effective, rugged and safe; RSD: Relative standard deviation; SALLE: Salting-out assisted liquid-liquid extraction; SD: Standard deviation

\section{Acknowledgements}

The authors highly acknowledge the financial support provided by the Higher Education Commission, Government of Pakistan under the Startup Research Grant Program (SRGP) (Grant No: PM-IPFP/HRD/HEC/2012/2792). The Department of Biotechnology, University of Malakand is also acknowledged for the provision of centrifuge.

\section{Authors' contributions \\ IS contributed to the main idea and implementation of the work by selecting the pesticide pinoxaden. MRJ helped to make the scheme of the experimental work and interpret the results. BA helped in the sample preparation and in providing chemicals for the interference study. SA helped in the statistical analysis of the data. HR helped in the pilot studies. All authors read and approved the final manuscript.}

\section{Competing interests}

The authors declare that they have no competing interests.

\section{Publisher's Note}

Springer Nature remains neutral with regard to jurisdictional claims in published maps and institutional affiliations.

\section{Author details}

'Department of Chemistry, University of Malakand, Khyber Pakhtunkhwa, Pakistan. ${ }^{2}$ Institute of Chemical Sciences, University of Peshawar, Khyber Pakhtunkhwa, Pakistan. ${ }^{3}$ Department of Statistics, University of Malakand, Khyber Pakhtunkhwa, Pakistan. 
Received: 6 February 2017 Accepted: 24 May 2017

Published online: 02 June 2017

\section{References}

Albert A, Kramer A, Scheeren S, Engelhard C. Rapid and quantitative analysis of pesticides in fruits by QuEChERS pretreatment and low-temperature plasma desorption/ionization orbitrap mass spectrometry. Anal Meth. 2014;6:5463-71.

Anastassiades M, Lehotay SJ, Štajnbaher D, Schenck FJ. Fast and easy multiresidue method employing acetonitrile extraction/partitioning and dispersive solid-phase extraction for the determination of pesticide residues in produce. J AOAC Int. 2003;86:412-31.

Anthemidis AN, Adam IS. Development of on-line single-drop micro-extraction sequential injection system for electrothermal atomic absorption spectrometric determination of trace metals. Anal Chim Acta. 2009;632:21620.

Anthemidis AN, loannou K-IG. Recent developments in homogeneous and dispersive liquid-liquid extraction for inorganic elements determination. A review. Talanta. 2009:80:413-21.

Anthemidis AN, Miró M. Recent developments in flow injection/sequential injection liquid-liquid extraction for atomic spectrometric determination of metals and metalloids. Appl Spec Rev. 2009:44:140-67.

Cai Y, Cai YE, Shi Y, Liu J, Mou S, Lu Y. A liquid-liquid extraction technique for phthalate esters with water-soluble organic solvents by adding inorganic salts. Microchim Acta. 2007;157:73-9.

Casas Ferreira AM, Fernández Laespada ME, Pérez Pavón JL, Moreno CB. Development of an environmentally friendly methodological approach to determine chlorinated hydrocarbons and chlorobenzenes in soils. Green Chem Lett Rev. 2014;7:50-9.

DeArmond PD, Brittain MK, Platoff GE, Yeung DT. QuEChERS-based approach toward the analysis of two insecticides, methomyl and aldicarb, in blood and brain tissue. Anal Meth. 2015;7:321-8.

Díez C, Barrado E, Marinero P, Sanz M. Orthogonal array optimization of a multiresidue method for cereal herbicides in soils. J Chromatogr A. 2008:1180:10-23.

García-Reyes JF, Ferrer C, Gómez-Ramos MJ, Fernández-Alba AR, Molina-Díaz A. Determination of pesticide residues in olive oil and olives. TrAC Trend Anal Chem. 2007;26(3):239-51.

Gilbert-López B, García-Reyes JF, Molina-Díaz A. Sample treatment and determination of pesticide residues in fatty vegetable matrices: a review. Talanta. 2009;79(2):109-28.

Gupta M, Jain A, Verma KK. Salt-assisted liquid-liquid microextraction with watermiscible organic solvents for the determination of carbonyl compounds by high-performance liquid chromatography. Talanta. 2009;80:526-31.

Hercegová A, Dömötörová M, Matisová E. Sample preparation methods in the analysis of pesticide residues in baby food with subsequent chromatographic determination. J Chromatogr A. 2007;1153(1):54-73.

Huang F, Guo Z-Y, Xu Z, Yang R, Lei J. Residue analytical method of cyhalofopbutyl and fenoxaprop-P-ethyl in water. Pesticides-Shenyang. 2007;46:248-54.

LeDoux M. Analytical methods applied to the determination of pesticide residues in foods of animal origin. A review of the past two decades. J Chromatogr A. 2011;1218(8):1021-36.

Lehotay SJ, Son KA, Kwon H, Koesukwiwat U, Fu W, Mastovska K, Hoh E, Leepipatpiboon N. Comparison of QuEChERS sample preparation methods for the analysis of pesticide residues in fruits and vegetables. J Chromatogr A. 2010;1217(16):2548-60.

Lin J, Chen J, Cai X, Qiao X, Huang L, Wang D, Wang Z. Evolution of toxicity upon hydrolysis of fenoxaprop-p-ethyl. J Agri Food Chem. 2007;55:7626-9.

Liu J, Jiang M, Li G, Xu L, Xie M. Miniaturized salting-out liquid-liquid extraction of sulfonamides from different matrices. Anal Chim Acta. 2010;679:74-80.

Matkovich CE, Christian GD. Solvent extraction of metal chelates into waterimmiscible acetone. Anal Chem. 1974;46:102-6.

Miro M, Estela JM, Cerda V. Recent advances in on-line solvent extraction exploiting flow injection/sequential injection analysis. Curr Anal Chem. 2005;1:329-43.

Noche GG, Laespada MEF, Pavón JLP, Cordero BM, Lorenzo SM. In situ aqueous derivatization and determination of non-steroidal anti-inflammatory drugs by salting-out-assisted liquid-liquid extraction and gas chromatography-mass spectrometry. J Chromatogr A. 2011;1218:6240-7.

Pena-Pereira F, Lavilla I, Bendicho C. Miniaturized preconcentration methods based on liquid-liquid extraction and their application in inorganic ultratrace analysis and speciation: a review. Spectrochim Acta B. 2009;64:1-15.
Razmara RS, Daneshfar A, Sahrai R. Determination of methylene blue and sunset yellow in wastewater and food samples using salting-out assisted liquidliquid extraction. J Ind Eng Chem. 2011;17:533-6.

Rejczak T, Tuzimski T. A review of recent developments and trends in the QuEChERS sample preparation approach. Open Chem. 2015;13(1):980-1010.

Rustum AM. Determination of diltiazem in human whole blood and plasma by high-performance liquid chromatography using a polymeric reversed-phase column and utilizing a salting-out extraction procedure. J Chromatogr B. 1989:490:365-75.

Shah J, Rasul Jan M, Shehzad FN, Muhammad M. Spectrophotometric method for quantification of fenoxaprop-p-ethyl herbicide in commercial formulations and agricultural samples. J Chem Soc Pak. 2010;32:537-41.

Shehzad FN, Shah J. Quantification of pinoxaden herbicide in wheat grains and vegetable samples by ultrasonication-assisted extraction and highperformance liquid chromatography. Pak J Weed Sci Res. 2013;19(2):167-77.

Siebers J, Besinger-Riedel A, Vinke C. Determination of active substances, coformulants and impurities in plant protection products using high performance liquid chromatography and gas chromatography. J Verbrauch Lebensm. 2014;9(2):137-44.

Song S, Ediage EN, Wu A, DeSaeger S. Development and application of saltingout assisted liquid/liquid extraction for multi-mycotoxin biomarkers analysis in pig urine with high performance liquid chromatography/tandem mass spectrometry. J Chromatogr A. 2013;1292:111-20.

Wilkowska A, Biziuk M. Determination of pesticide residues in food matrices using the QuEChERS methodology. Food Chem. 2011;125(3):803-12.

Zhang J, Wu H, Kim E, El-Shourbagy TA. Salting-out assisted liquid/liquid extraction with acetonitrile: a new high throughput sample preparation technique for good laboratory practice bioanalysis using liquid chromatography-mass spectrometry. Biomed Chromatogr. 2009;23:419-25.

\section{Submit your manuscript to a SpringerOpen ${ }^{\mathcal{O}}$ journal and benefit from:}

- Convenient online submission

- Rigorous peer review

- Open access: articles freely available online

- High visibility within the field

- Retaining the copyright to your article

Submit your next manuscript at $\gg$ springeropen.com 